\title{
The Hangul in Dachigam: a Census
}

\section{Colin Holloway}

The object of Dr Holloway's two visits to Kashmir was to draw up a management plan for the Dachigam Sanctuary, the main habitat of the highly endangered hangul, or Kashmir stag. This includes a plan of work for the next five years, and also provision for anti-poaching patrols, the prevention of illegal grazing, wood-cutting and fires, staff training and a research programme. Dr Holloway is staff ecologist with IUCN.

The hangul, Cervus elaphus hanglu Wagner, hitherto generally but confusingly called the Kashmir stag, is a critically endangered deer (Simon 1966).* The report on the IUCN pre-assembly study tour of Dachigam Sanctuary, in November, 1969, estimated that only 150-200 hangul survived in this area. It identified poaching as the principal cause of decline and recommended that a further visit be made to the area in February, 1970, to prepare a management plan and to conduct a more accurate count of the deer (Holloway and Schaller, 1970).

On February 9th-21st, 1970, the writer returned to Kashmir to undertake these tasks. The plan (Holloway and Wani 1970) is currently under consideration by the Jammu and Kashmir Government, and this article records the results of the census and other data collected on the distribution, biology and behaviour of the hangul.

A distribution map of the hangul, prepared for the Maharaja of Jammu and Kashmir earlier in the century, describes an arc of some 40 miles in width to the north and east of the Jhelum and lower Chenah rivers, from Shalurah in the north to Rhamnagar in the south, which, in general terms, accords with the distribution given by Lydekker (1924). Unconfirmed reports of animals sighted during 1969-1970 suggest that small remnant groups still occur within this range, particularly in the north (A. R. Wani pers. comm.). The Gamgul Siya-Behi Sanctuary in Himachal Pradesh, on the State border, is the only area outside Jammu and Kashmir that probably retains a few hangul. The deer still survives in Desu Sanctuary, some 70 miles to the south-east of Srinagar, in the Upper Bring valley; two separate groups of half a dozen hinds and calves were observed on 30 th June, I970 ( $R$. Waller pers. comm.).

The only area in which a truly viable population has been confirmed, however, is Dachigam Sanctuary, an area of approximately 55 square miles, to the north east of Srinagar. It comprises the valley and catchment zone of the Dagwan river and its altitude range is from 5,500 feet

* This sub-species of red deer has three common names: hangul (its Kashmiri name), Kashmir stag and barasingha. The last is also used for the swamp deer Cervus duvauceli and the use of the name Kashmir stag causes confusion when referring to females and young. The name hangul (it rhymes with jungle) is therefore to be preferred.

A general account of the Kashmir stag and its status is in Lee Talbot's $A$ Look at Threatened Species, ORYX, 1960, 5, 4. Editor. 


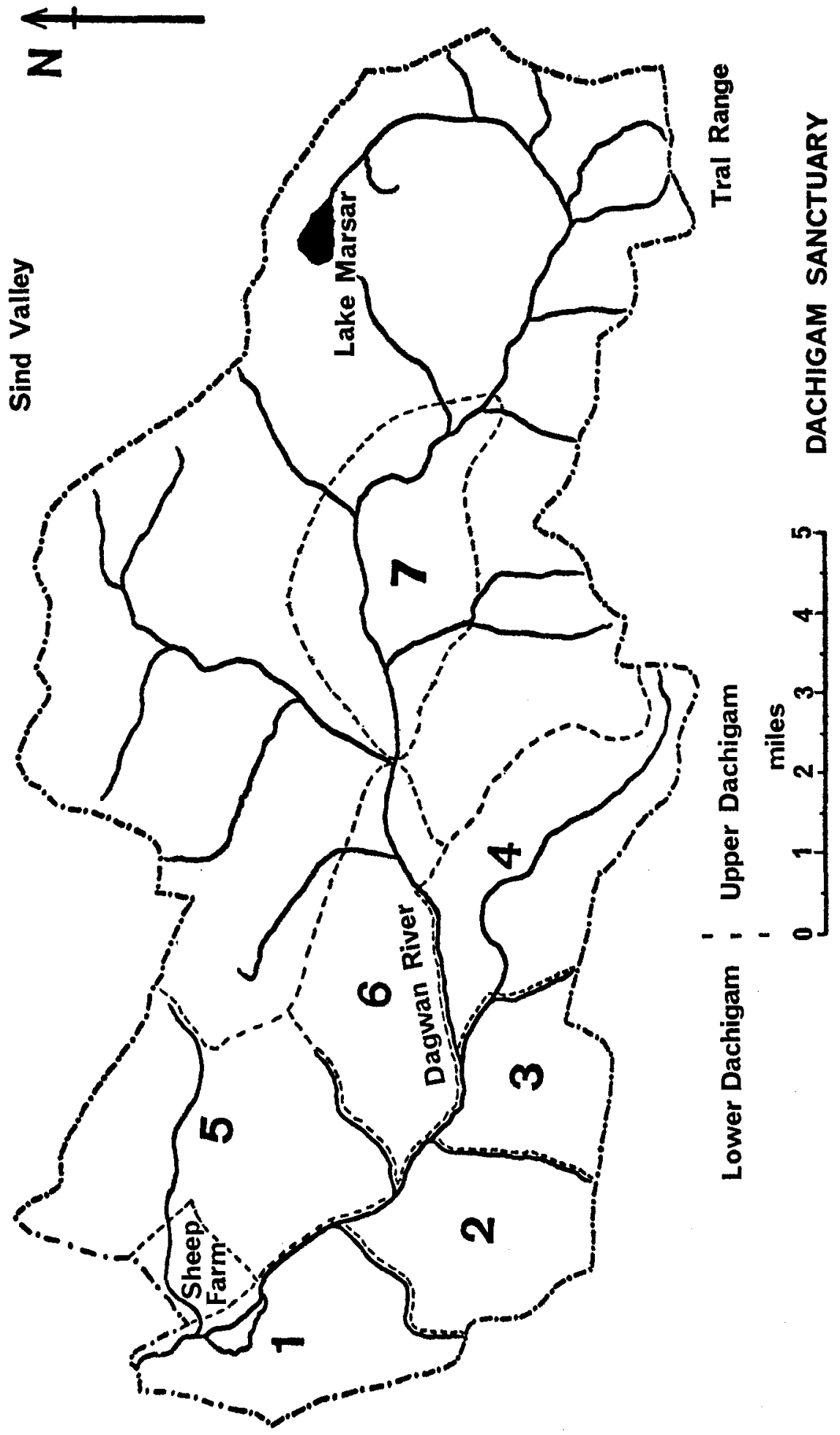


in the west to 14,070 feet at the south-east boundary point. The sanctuary is divided into two sectors, Lower Dachigam in the west, which comprises a third of the total area, and Upper Dachigam in the higher reaches of the east.

The valley floor is narrow and carries a riverain forest principally of broad-leaved genera (e.g. Morus, fuglans, Robinia, Populus, Salix, Rhus, Quercus and Acer) many of which have been introduced. Between 6,000 and 9,000 feet, grasslands cover much of the south and south-west facing slopes, whilst on the northerly aspects there is a broad-leaved woodland the main genus of which is Parrotia, although Aesculus, Corylus and Acer are common in places. Pinus excelsa occurs throughout this range as scattered open woodland at low elevations, but forming a continuous canopy at higher altitudes, particularly on southerly aspects. Coniferous forest occurs from 8,500 to 10,500 feet. Abies pindrow is largely confined to the moister northerly aspects and Picea morinda to southerly aspects. The latter predominates at higher altitudes. The alpine pastures, dotted with patches of funiperus scrub, occur above 10,000-I I,000 feet.

The area was one of the Maharaja's hunting reserves from about I9ro until 1947, when its management reverted to the Forest Department. It was declared a sanctuary in 1951. There are no accurate data on the former numbers of hangul. During the latter half of the Maharaja's time, estimates by the sanctuary guard force put the total population in this region at approximately $3,000(\mathrm{Q}$. Wani pers. comm.). The figure is very high but at that time the reserve included much of the surrounding forests, protection was rigid, and in Lower Dachigam, at least, forage crops were planted for the deer and they were fed during winter. There is little doubt that numbers have declined drastically since 1947 (Gee, 1966; Schaller, 1969).

Land to the east of the sanctuary consists of open rocky pasture for five miles and there are three main traditional wintering grounds for hangul in this region: the Sind valley to the north-east of the sanctuary, the Tral Range in the south-east, and Lower Dachigam in the west.

\section{Methods and Procedure}

February was selected as the month for the census because, in an average winter, accumulations of snow at high altitudes drive the hangul down to the main Dagwan river valley and its lower slopes. Unfortunately, the 1969/1970 winter proved to be exceptional. Only two falls of snow had occurred before the writer's visit: the first in late December and the second on January 29th. By February 9 th, most snow cover on the open south-facing slopes of Lower Dachigam had disappeared.

Certain assumptions were made in determining the census area and the procedure for the count. The land outside Lower Dachigam consists of heavily grazed pasture, cultivation or high rocky ground, which provide little winter forage and no cover. Dara Forest in the north-west is an exception, and arrangements were made for a separate check of this area. According to local staff, diurnal movement is pronounced in the hangul, an observation that was generally confirmed by experience in November, 1969. The alpine pastures still had a virtually continuous 


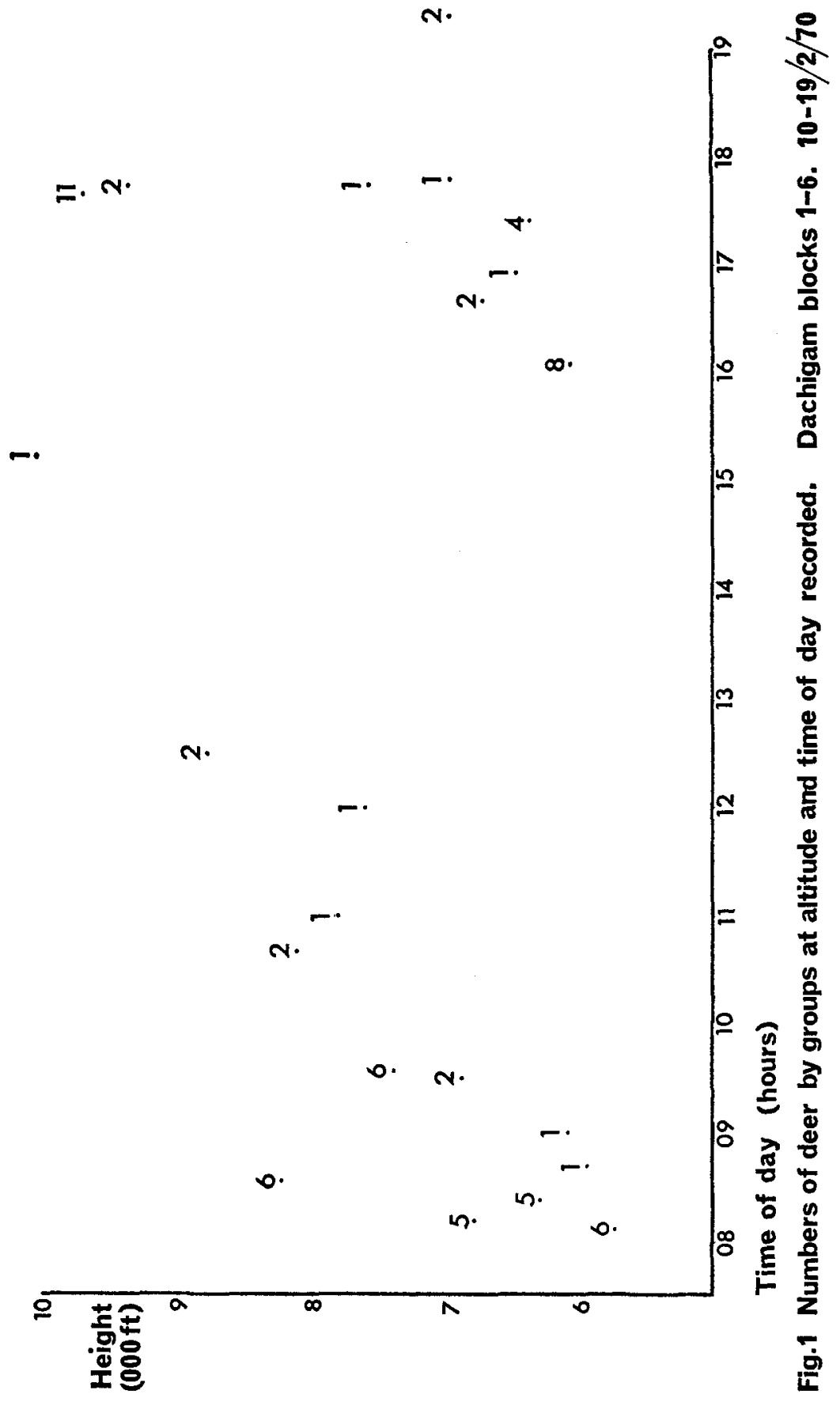


cover of snow and it was known that the Abies/Picea forests had little ground vegetation. Although hangul might shelter in these areas during the day, it was assumed that most animals would move diurnally to lower altitudes to feed, and that morning and evening observations on the hill flanks would enable sightings that might otherwise be missed.

The senior game guard had spent some months watching hangul in the southern part of Lower Dachigam. He reported that certain groups had established themselves in the tributary valleys and that they rarely crossed the main ridges into adjacent valley systems. If this information were correct, and provided the deer suffered no undue disturbance from man or the weather during the census period, then blocks of the sanctuary could be censused in sequence without serious risk of counting the same animals twice.

For these reasons the census was largely confined to land within the sanctuary boundaries below 9,000 feet. It was subdivided into seven blocks (see map $\dagger$ ) and each of blocks $I-6$ was walked on consecutive days by the census party, which consisted of the writer, the forester and the senior game guard, each of whom had binoculars $(7 \times 50,8 \times 30$ and IO $\times 50$ ). The ascent of each block began soon after daybreak ( 07.00 hours) and was normally completed by nightfall (18.15 hours). The Dagwan valley was sufficiently narrow to permit detailed observation of hillsides opposite to the areas being walked,so that most hill flanks were scrutinised on more than one day. The party stayed together except when splitting was essential to ensure that ground was covered adequately. With two exceptions, only animals that were seen or heard were recorded. It was possible to distinguish stags from hinds and followers

Table 1

Numbers of Hangul recorded in Blocks 1-6, Dachigam, 10th-19th February, 1970

\begin{tabular}{cccrrr}
\hline $\begin{array}{c}\text { Block } \\
\text { No. }\end{array}$ & $\begin{array}{c}\text { Approx Area } \\
\text { (acres) }\end{array}$ & $\begin{array}{c}\text { Max. Alt. Reached* } \\
\text { (feet) }\end{array}$ & Stags & $\begin{array}{c}\text { Hinds \& } \\
\text { Followers }\end{array}$ & Total \\
\hline I & 2,050 & 8,550 & 7 & 21 & 28 \\
2 & 2,000 & 9,200 & 2 & 5 & 7 \\
3 & 1,490 & 9,200 & 2 & 3 & 5 \\
4 & 2,900 & 9,400 & 4 & I I & I5 \\
5 & 4,340 & 10,500 & 1 & I4 & I5 \\
6 & 2,530 & 9,200 & 2 & 0 & 2 \\
\hline & & & I8 & 54 & 72 \\
\hline
\end{tabular}

* by observers; effective observation to higher altitudes was often possible.

57 of the 72 animals recorded were actually seen, 12 were heard (disturbed) and their numbers compiled from tracks in snow, and 3 stags were recorded from tracks made within the hour in areas where no other stags were seen.

$\dagger$ The boundaries shown for Block 7 are approximate. 
Table 2

\begin{tabular}{llccc}
\hline \multicolumn{4}{c}{$\begin{array}{c}\text { Numbers of Hangul recorded in Block 7, } \\
\text { Upper Dachigam, 23rd-27th February, 1970 }\end{array}$} & Total \\
\hline Sub-block & $\begin{array}{c}\text { Approx. Area } \\
\text { (acres) }\end{array}$ & Stags & $\begin{array}{c}\text { Hinds \& } \\
\text { Followers }\end{array}$ & (on \\
\hline Gonasnar \\
$\left.\begin{array}{l}\text { Namblan } \\
\text { Goipathri }\end{array}\right\}$ & 4 & 22 & 26 \\
& 2,700 & 1 & 4 & 5 \\
& 0 & 12 & 43 \\
\hline
\end{tabular}

(yearlings and calves) that were disturbed without being seen from their tracks in the snow. Records were kept of tracks, faecal pellet groups and lairs (bedding places), and distances walked were subsequently computed from a map. Two days were spent in block $\mathrm{I}$ and one day in each of the remainder. Block 7 was to have been reconnoitred by guards from the Tral Range and, if their report was favourable, was then to be visited by the census party. Apparently, the message never reached the guards and this area was censused by the forester during the week of February 21st-26th. On 21st February, 1970, the game warden organised a drive census of the riverain forest in the Lower Dagwan valley, and the writer visited the Tral Range on 2oth-2Ist February, 1970.

\section{Results}

Visibility in the sanctuary during the census period was excellent; the air was remarkably clear and there was bright sunshine each day. The deciduous woodland had lost its leaves and a cover of snow under the trees made for easy observation. The forest floor of the pinewoods also had a cover of snow and the general absence of lower side branches enabled one to see for good distances once inside these forests.

The drive census of the riverain forest strip between the sanctuary's western boundary and Pahlipora Bridge (the eastern boundary point of block 4) recorded 6 hinds and followers. The area is approximately 1,000 acres. The Dara Forest staff reported 4 hangul (sex not recorded); the animals had apparently remained there since the beginning of the winter. The largest herd, seen in block 5, consisted of 9 hinds and followers and 2 stags. Figure I (ref. next section) shows the number of hangul recorded in each group in blocks $I-6$ plotted against the time of day and altitude at which they were recorded. Table 3 shows the main vegetation types in which they occurred.

The visit to the Tral Range confirmed Schaller's (1969) view that the area is unsuitable nowadays for large-scale wintering by hangul because of human disturbance. The local staff considered that about 25 hangul, in four or five groups, usually wintered in this area. They stated that 
Table 3

\begin{tabular}{cccc}
\hline \multicolumn{2}{c}{ Numbers of Hangul in Main Vegetation Types, Blocks 1-6, } \\
Dachigam, 10th-19th February, 1970
\end{tabular}

* Number of observations

considerably larger numbers of hangul from Upper Dachigam wintered in the Sind valley. On 21st February, 1970, fresh tracks of 2 stags and I hind were found below the south-east boundary of the sanctuary, near Gagiari, at II,IOO feet (the highest point at which hangul tracks were seen during the census period).

\section{Discussion and Conclusions}

There was no evidence of marked mobility among deer during the census period. Indeed, the position, size and composition of groups recorded in block I tallied almost exactly with the arrangement that was said to have existed in this area since December, 1969. The situation on the north slopes, where deer were higher and movement between adjoining ridges was easier, or in the east, where movement might be more readily influenced by sudden changes in weather, is uncertain. Nevertheless, the circumstances under which deer were recorded in these areas largely eliminated any risk of recording animals twice.

The deer counted during the drive census in the Dagwan river valley, on the other hand, could have been recorded in surrounding blocks and they have been excluded from the total count. The animals in Dara Forest are also excluded because they probably stay outside the sanctuary during winter. Similarly, few, if any hangul wintering in the Tral Range or Sind valley would be likely to re-enter the sanctuary during winter (the north and south-east boundaries of Upper Dachigam occur between 10,500 and 14,000 feet altitude).

The count in block 7 took place over the course of a week, which reduces the probability of animals being missed but increases the chances of double counting. The numbers recorded are high, but the block probably forms the main winter feeding area for deer over much of Upper Dachigam. On the assumption that the counting procedure adopted in Lower Dachigam was strictly applied in block 7 , these figures are accepted in the total count.

The minimum number of hangul present in Dachigam in February, 1970 , therefore, is II5.

In the graph, groups of hangul in blocks $I-6$ have been plotted against the altitude and time of day at which they were recorded. Although the observers' movements followed that of the deer, much of the range of altitudes considered were under some degree of observation throughout 
the day. If diurnal movement were common, the points on the graph should lie about an inverted U-shaped curve. The data are from a number of different valleys whose lowest and highest points differ by up to 500 and $I, 500$ feet respectively. It is not one curve that is being considered, therefore, but a set of roughly parallel curves, hence the wide scatter of points. The main movement appears to start within $\mathrm{I} \frac{1}{2}$ hours of daylight (07.30-09.00) and dusk ( $\left.16.30-18.00\right)$ and to continue for the next $I \frac{1}{2}$ hours. Animals at high altitudes probably complete their descent in darkness when few observations were possible, which may account for the irregularity of the evening observation points compared with those of the morning.

It is highly unlikely that all hangul move between the valleys and the hills every 12 hours (three of the animals counted in the Dagwan river valley were observed well after 10.00 hours) or that all animals that begin a descent necessarily reach the main valley. It seems reasonable to assume, however, that although some hangul occur at the tree line (10,500 feet) during the day, many animals move into the census areas $(9,200$ feet and below) at night, and that there would be few indeed that would not have descended to these areas during the snowfall on January 29th. Provided no substantial area below 9,000 feet was neglected, therefore, signs of activity within these blocks should give some indication of the total animals present in the sanctuary as a whole.

A proportion of the Dachigam hangul population was undoubtedly missed in the census. The animals lost comprise those that were present in the blocks during the count but which escaped detection, and those which descended only as far as the upper parts of the census area at night and had moved up again before the area could be examined by the census party (the latter problem is confined to blocks on the north slope and in the east). Subjective estimates of these animals were made for blocks $2-6$ based on fresh (day-old) signs of activity at all altitudes, and also on signs of sustained activity, that were not continued at lower elevations, at high altitudes. No adjustment was calculated for block 7, because no detailed information on the area was available, or for block $\mathrm{I}$, because there was good reason to believe that no animals had been missed. The maximum and minimum estimates of hangul that could have been missed in blocks $2-6$ are 55 and 23 respectively.

It is estimated, therefore, that the total number of hangul in Dachigam in February 1970 lies between 140 and 170 . The writer considers that the lower figure is the better estimate for hangul that occurred in the census blocks, but as no adjustment was calculated for block 7, which is surrounded by a large area in which no counts were made, the true figure for the sanctuary as a whole probably lies nearer to 170 . In summer the number of hangul in the sanctuary is very probably increased by the addition of animals that have wintered in the Sind valley and Tral Range. The extent of the increase is unknown. According to R. Sinh (pers. comm.) not all the animals in the Sind valley summer in Upper Dachigam, and some animals from the latter area move across the Dachigam-Liddar divide and summer between Liddarwat and Arau, in the east. 


\section{Additional Notes}

Three hind groups observed during the census had a pair of mature stags either with them or in their immediate vicinity. According to the game guard, this association is fairly common for much of the year, except in the rut. The stag association is apparently an amicable one, although on Ioth February, 1970, one such pair were observed bickering and one stag finally chased the other off. Observations, both of animals and tracks, suggest that by far the commonest stag grouping is two, although larger bachelor groups occur (the forester observed a group of 5 stags in block 6 on 31st January, 1970). In blocks I-6, stags appeared to be rather more numerous than hinds, whereas the count in block 7 suggests that the situation may be reversed at higher altitudes. There is certainly no marked disparity in the sex ratio (see Gee, I966) and the evidence supports Schaller's (1969) opinion that in 1968 males and females appeared to be present in about equal numbers. Calf production appeared to be good in all areas except block $I$, where only two of the 22 hinds and followers could be positively identified as calves, although there were a number of yearlings present.

Large tufts of hair were found in several bedding places and 'dust wallows' used by hangul. A superficial examination of the hair revealed nothing unusual in its condition or content. February is clearly too early for winter coats to be shed and, in any case, similar tufts of hair were found near the Dagwan river in November. On I9th February, I970, a mature hind was observed with a raw patch, about four inches in diameter, above its foreleg; the animal appeared to be in good health.

Young trees that had been damaged by fraying and threshing with antlers were surprisingly common on the periphery of some pine forests. The occurrence of 'rubbing trees' (on which deer rub their bodies) was of particular interest in view of their supposed rarity outside the red deer areas of Scotland. The trees carried coatings of hair and were of similar sizes and occurred in similar situations to rubbing trees in the Scottish Highlands. An antler was found in block 6 from which the top and one tine had been gnawed. The tooth marks strongly suggested that it had been chewed by deer.

At one point it had been hoped to use counts of faecal pellet groups (where deposited on snow, to eliminate problems of estimating their age) as a method of calculating estimates of hangul numbers. The distribution of pellet groups proved to be very markedly clumped, however, and the plan was abandoned. A few pellet groups (from their appearance, deposited by the same animal within a short space of time) contained about four or five times the average number of pellets. They all appeared to have been deposited by hinds and while some were found in rocky or wooded areas, where the animal may have been forced to shelter in bad weather, at least one group occurred on an open, unsheltered hillside.

The carcase of a hind was discovered during the drive census of the Dagwan river valley on 2Ist February, 1970. The throat had been torn out and the body partially eaten. It was assumed to have been killed by a snow leopard a few days earlier (A. R. Wani pers. comm.). The census party had observed a snow leopard in the same general vicinity, in 
block I, at I4.Io hours on IIth February, 1970. It was prowling along an open ridge at 7,020 feet.

Evidence of a poaching party was discovered near the southern boundary of block 3 ; the tracks of four or five men were found following the tracks of two stags. Hopefully, implementation of the new management plan for Dachigam will put an end to this practice.

\section{Acknowledgments}

I am extremely grateful to the World Wildlife Fund for financing my visit to Kashmir, to the Jammu and Kashmir State Forest Service for the provision of transport during my stay, and to Mr. A. R. Wani (Game Warden, Srinagar), Mr. O. N. Kaul (Forester, Dachigam) and Mr. Q. Wani (Game Guard, Dachigam) for providing me with much help, information, and good company during the survey of the sanctuary.

\section{References}

GeE, E.P., I966. Report on the status of the Kashmir stag; October I965. J. Bombay Nat. Hist. Soc. 62(3): 379-393.

Holloway, C.W. and G.B. SchalleR, I970. Status and management of the hangul. IUCN IIth Technical Meeting, Proceedings. IUCN Pub. New Series. I9 (3).

Holloway, C.W. and A.R. WANI, 1970. Management plan for Dachigam Sanctuary, I97I-I975. Cyclostyled. $26 \mathrm{pp}$.

LYDEkKER, R., 1924. The Game Animals of India, Burma, Malaya and Tibet. Rowland Ward, London. 412 pp.

SCHALlER, G. B. 1969. Observations on the hangul or Kashmir stag, (Cervus elaphus hanglu. Wagner). J. Bombay Nat. Hist. Soc. 66 (I): I-7.

Simon, N. I966. Mammalia. IUCN Red Data Book, Vol. I.

\section{Tiger Hunts Banned in India}

The shooting of tigers has now been banned in the whole of India: the last state to do this was Uttar Pradesh, which has a large proportion of the tigers. This hunting ban was strongly urged at the IUCN general assembly in New Delhi last December, when tiger numbers were estimated to have dropped to as low as 2500 for the whole sub-continent. The export of skins was prohibited two years ago. It is hoped that Nepal, where tigers are also seriously depleted, will also now ban shooting.

\section{First National Park for Lesotho}

Lesotho, formerly Basutoland, established its first national park early this year. The 25 -square-mile Sehlabathebe park, 8500 feet up on a plateau bordering Natal and the Cape Province, is being developed with the aid of the South African Wildlife Foundation, which has made a grant for fencing the area and for equipment. It is planned to re-introduce some large mammals on the good grazing in the park; the birds already include two rare African species, the bald ibis and the lammergeyer. 